\title{
EDUCATION AND TRAINING Perceived educational impact, challenges and opportunities of hospice placements for foundation year doctors: a qualitative study
}

\author{
Author: Sarah Frearson ${ }^{A}$
}

Foundation year one doctors (F1s) are expected to recognise and care for dying patients, but previous studies have found they can feel unprepared, stressed and unsupported when faced with such situations. Although hospice placements can provide good experiential learning for junior doctors, no studies to date have included F1s. This study used an interpretivist approach to explore educational opportunities and challenges in hospice placements from an F1's perspective. Six F1s who had recently completed hospice placements were interviewed individually. Data analysed qualitatively showed that F1s valued informal experiential learning and felt well supported by senior doctors. The most important learning outcome was the acquisition of enhanced communication skills and challenges included the risk of becoming medically deskilled. F1s felt their medical practice had changed as a result of hospice placement, most commonly in communication skills and recognition of the dying phase. The author recommends increased utilisation of hospice placements in foundation training programmes.

KEYWORDS: Foundation year, junior doctor, hospice, end of life, palliative care

\section{Introduction}

General Medical Council guidance in Outcomes for graduates stipulates that they should be able to "contribute to the care of patients and their families at the end of life, including management of symptoms. ${ }^{1}$ The UK Foundation Programme covers the first two years following graduation from medical school. It has a spiral curriculum comprising a core of twenty outcomes, one of which is 'manages palliative and end-of-life care under supervision. ${ }^{2}$ In theory a hospice placement could be an ideal opportunity for foundation year one doctors (F1s) to prepare to meet this outcome. However, such placements remain a rarity in foundation programmes, with the Association for Palliative Medicine including only one $\mathrm{F} 1$ post in their 2016 workforce survey. ${ }^{3}$

Author: ${ }^{\text {A }}$ palliative medicine consultant, Imperial College Healthcare NHS Trust, London, UK
Palliative care teaching in medical schools can be fragmented, and is rarely formally assessed. ${ }^{4}$ Emphasis is placed on how to improve health, with little teaching on what to do when this fails. ${ }^{5}$ Newly qualified doctors can feel unprepared, unsupported and even distressed when caring for dying patients. ${ }^{6,7,8}$ They have described 'being left' to cope, fearful that their lack of experience could make things worse for patients. ${ }^{9}$ Palliative care is often learnt on the job, with little formal teaching. ${ }^{10} \mathrm{~F} 1 \mathrm{~s}$ can find communication about end-of-life decisions and recognition of the dying phase challenging and can also lack knowledge of cancer care and symptoms. ${ }^{11,12,13}$ There is a perceived lack of senior medical support when caring for dying patients in hospital placements. ${ }^{12,14}$ However, support from other team members, in particular nursing teams and senior doctors, can significantly enhance learning environments. ${ }^{15}$

Few studies have looked at junior doctor placements in hospices. One study found that senior house officers (SHOs) considered there to be excellent experiential learning opportunities in UK hospice placements, but this was tempered by feelings of being isolated from their peers, and emotional toll. ${ }^{16}$ Another study involved six F1s mostly in split oncology and palliative medicine hospital posts, where it was reported that although such placements helped develop skills in diagnosing dying and breaking bad news, split posts and on-call rotas could detract from the positive educational experience. ${ }^{17}$ The current study took an interpretivist approach aiming to explore individual F1 opinion of hospice placements, in order to provide some insight into this under-researched area.

\section{Methods}

The study setting was a 16 -bedded UK hospice. Six F1s each year have an 8 week long placement, with no on call commitments and limited contact with other F1s. Using a purposive sampling technique all F1s who had a hospice placement between August 2016 and March 2018 were invited to take part in the study. The researcher, a hospice consultant, had an established professional relationship with participants as their former clinical supervisor. Professional relationships can compromise voluntary informed consent. ${ }^{18}$ To limit this, an opt-in recruitment strategy was chosen whereby participants were contacted via email by a third party (an educational administrator) and asked to email the researcher if interested in participation. Of the eight F1s contacted, six gave 
Table 1. Participant demographics

$\begin{array}{lllll}\text { Pseudonym } & \text { Sex } & \text { Grade at interview } & \text { Time since placement } & \text { Career aspirations } \\ \text { Dr A } & \text { Male } & \text { F1 } & 1 \text { day } & \text { Psychiatry or general practice } \\ \text { Dr B } & \text { Female } & \text { F1 } & 2 \text { months } & \text { General practice } \\ \text { Dr C } & \text { Male } & \text { F1 } & 4 \text { months } & \text { General practice } \\ \text { Dr D } & \text { Male } & \text { F2 } & 7 \text { months } & \text { General surgery } \\ \text { DrE } & \text { Female } & \text { F2 } & 9 \text { months } & \text { Anaesthetics } \\ \text { DrF } & \text { Female } & \text { F2 } & 15 \text { months } & \text { Radiology }\end{array}$

written consent to be part of the study, and two decided not to participate because of time constraints.

Individual participants chose the location for their interview; four decided to use the education department facilities in their base hospital, one chose the hospice secretarial block, and one opted to be interviewed at home. Face-to-face individual interviews were performed by one researcher who had previously been participants' educational supervisor. In order to mitigate any restriction in response due to the power balance between interviewer and interviewee, power balance was acknowledged at the beginning of each interview and participants reminded that the researcher's role in this instance was to gather opinion not to act as an educational supervisor. ${ }^{19,20}$

Individual interviews were chosen as the data collection method because in-depth interviews allow detailed exploration of opinion, impact and outcomes from an individual perspective. ${ }^{21}$ Secondly, hospice placements are likely to be complex experiences, and these types of experience are generally better explored using individual interviews. ${ }^{22}$ Semi-structured interviews, using an interview guide were chosen for their ability to provide consistency and to ensure relevant topics are covered, whilst allowing flexibility to pursue topics important to individual participants. ${ }^{22}$ The interview guide was piloted on a junior hospice doctor not otherwise involved in the study. Participants were asked about learning needs, educational opportunities, challenges and changes in practice (supplementary material S1). An array of prompts, probes and checks tailored to each individual were used to explore topics in detail or clarify meaning. ${ }^{21}$ Field notes were made of non-verbal communication and reflective notes of initial impressions and themes were written following interview. ${ }^{19}$

Interviews were audio-recorded and then transcribed verbatim. Using an inductive approach transcripts were analysed by a single researcher using a qualitative thematic approach. ${ }^{22}$ Transcripts were read iteratively until themes emerged from the data. Themes were structured via codes into an index which was adjusted until all relevant concepts from all interviews were assigned a code (supplementary material S2). This index was then applied across the data set and themes sorted into a framework to allow easy comparison across and between themes and participants. Any outlier responses were examined and their relevance carefully considered. Data saturation was reached with no new themes emerging after five interviews. To add rigour, a second qualitative analysis was performed using a constant comparator approach. ${ }^{23}$ Two transcripts were randomly chosen and similarities and differences between them considered. This process was then repeated with the introduction of a third and then subsequent transcripts. As the results from both methods of analysis were concordant, with the thematic analysis providing most detail and the constant comparator illustrating contentious issues, they were merged for analysis purposes. Respondents were emailed a copy of the results and asked for their validation of the findings.

This project was screened by UCL Research Ethics Committee and considered exempt from full ethical review. NHS trusts and training programme directors were informed of the study and gave their permission for it to proceed. The study complies with the Consolidated Criteria for Reporting Qualitative Research. ${ }^{24}$

\section{Results}

Six F1s participated who had completed a hospice placement between one day and fifteen months prior to interview (Table 1).

Six main themes emerged from the data.

\section{1: Learning environment}

The learning environment at the hospice was considered supportive with an emphasis on teaching. Most participants discussed having time to be thorough and to hone key skills. Participants felt staff were supportive and available, which gave them confidence; Dr D:

I did feel confident enough to take a history from a patient because I knew I had my seniors and everybody else available.

\section{2: Learning needs}

Communication skills were mentioned by all participants as their predominant learning need; Dr F:

Talking to patients... I was terrified about, I remember thinking 'These people are dying; I have to talk to them.'

Only one participant (who had a career break between medical school and F1) viewed some of his learning needs as unmet; $\operatorname{Dr} C$ commenting, 'at least $90 \%$ were met'.

Most of the participants brought up gaps in knowledge and experience. Several discussed a lack of palliative care teaching at undergraduate level, describing being actively kept away from dying patients; Dr F:

If you say, 'Can I go clerk a patient?' They would say, 'Don't go to that room, they are palliative care, it's not very appropriate for you to talk to them.' So, you don't really see it at all.

Participants spoke at length about the difficulties of delivering good palliative care in hospitals. Most had experienced a lack of important end-of-life decision making and some even spoke of instances where dying patients were missed out on ward rounds. 


Box 1. What foundation year 1 doctors can learn at
the hospice
$>$ Communication
$>$ Prescribing at the end of life
$>$ How to take a palliative history
$>$ Recognising dying
$>$ Management of complex palliative patients
$>$ Understanding of hospices and palliative care as a specialty
$>$ The value of a good death
$>$ How to write discharge summaries
$>$ Procedures

Others raised a lack of teaching and opportunity to practise communication skills; Dr A:

It didn't even come to avoiding it, we just didn't have that opportunity... we weren't really allowed to discuss it.

\section{3: Learning opportunities}

All participants spoke positively about learning opportunities at the hospice (Box 1).

Dr E sums up the group feeling by commenting:

By far and away the greatest emphasis was placed on communications kills.

All participants considered management of complex patients, prescribing at the end of life and gaining a general understanding of hospices and palliative care as important additional areas of learning.

Participants viewed informal learning opportunities to be of greater value than formal, and spoke extensively about informal opportunities to learn communication skills, through observation of senior doctors and practising these skills themselves; Dr A:

The first few weeks it was mainly observing the other doctors and seeing how they do it and then after that I got the opportunity to do it myself as well. You learn from both.

The role of senior doctors in education was discussed at length, including teaching on ward rounds, role modelling, feedback and educational sign-posting. F1s valued being given responsibility to clerk new patients and discuss possible management plans with senior doctors.

\section{4: Potential challenges}

Most participants identified emotional toll as a potential challenge, yet none of the participants felt this had affected them personally during their placement. The reasons for this varied from being older, feeling supported and the short placement duration. One participant felt the hospice was a positive place, another felt as long as he was doing the best for patients, he didn't feel emotionally drained; Dr F:

I didn't feel that the hospice was a sad place, I felt the exact opposite, I felt it was a very positive place... I genuinely never came home feeling that was an emotionally draining day.
Some participants felt they had ample opportunities to use their clinical skills; others (with career aspirations in anaesthetics and surgery) missed performing complex procedures. The potential for becoming medically deskilled was a contentious issue; three participants felt strongly they were not deskilled; others felt slightly deskilled in acute medical competencies, but agreed this was outweighed by gaining alternative additional skills; Dr F:

I think I got competent in other ways... there was a whole skill set that we got that they don't have.

None felt personally affected by a lack of peer support; most found either medical or nursing staff provided this, or that contact with other F1s in weekly teaching sessions or social media groups was sufficient.

\section{5: Change in practice}

Everyone agreed that their hospice placement had changed or would change their practice, most commonly through the acquisition of communication skills. However, better recognition of the dying phase, end-of-life pharmacology and management of complex patients were also mentioned, as was knowledge of when and how to refer to hospital palliative care teams. F1s came to recognise that palliative care was an active process rather than simply withdrawing medical treatment; $\operatorname{Dr} A$ :

Actually, there is quite a lot you can still do in terms of management and investigations for the [palliative] patients which beforehand I probably didn't recognise fully.

One participant felt that his knowledge in end-of-life care could not be utilised as this was the job of the hospital palliative care team. However, the others disagreed with this, feeling that they had developed important transferable skills; Dr F:

Whatever job you are in you can transfer it, at some point in your life you are going to encounter dying patients.

Two F1s who had their placement many months prior to interview described extensive changes in practice after their placement, and they also reported becoming increasingly aware of this as time went on. Both felt confident to challenge others in their management of patients at the end-of-life and to prompt end-of-life discussions.

\section{6: Recommendation of hospice placement and suggestions for improvement}

All participants would recommend a hospice placement. They believed that the skills they had gained were important and could not be learnt elsewhere; $\operatorname{Dr} A$ :

I think you learn stuff in this job that you wouldn't learn on a general medical rotation or surgical rotation or whatever.

When asked for suggestions to improve hospice placements, participants most often suggested being given more responsibility.

\section{Discussion}

This study is the first of hospice-based F1s and demonstrates that such placements can enable F1s to gain confidence in end-of-life care and communication - areas that newly qualified doctors may 
find challenging. ${ }^{6,7,8}$ As other studies in similar settings have found, participants valued experiential, informal learning opportunities, particularly when interacting with patients and other staff. 9,10,16,17 Here, this experiential learning was achieved with suitable support from staff, but in other studies learning on the job has been described by junior doctors as being through making mistakes and being 'thrown in at the deep end. ${ }^{5,10}$ F1s placed emphasis on the role of senior doctors in informal learning. Although already extant, this finding underlines the important educative role senior doctors have in supporting and teaching newly qualified doctors. ${ }^{10,14,17}$ Some of the most valued learning opportunities were patient-related, for example, when given responsibility to do challenging tasks such as clerking new patients. Other research has also identified the importance of patient (or client)-centred tasks, being given responsibility and completing challenging tasks when learning in a workplace. ${ }^{15,25,26} \mathrm{~F} 1 \mathrm{~s}$ were able to identify informal learning opportunities and describe how they had learnt from them. This is in contrast to other research on workplacebased learning which has described informal learning as invisible, tacit and complex. ${ }^{25}$

Many of the other findings here replicate those from other studies. For example, communication skills have been acknowledged as a predominant learning need for junior doctors along with recognition and symptom control of dying patients. ${ }^{13}$ Gaps in education and experience in both communication skills and palliative care have also been recognised previously, and other study participants have described being afraid of talking to dying patients and not knowing how to care for them. 5,6,7,9 The limitations of providing palliative care in hospital settings, with dying patients being missed on ward rounds and given aggressive treatments have also been previously reported. ${ }^{5,13}$ All participants felt that their hospice placement had or would change their practice, mainly through acquisition of transferable skills such as communication skills, improved recognition of dying and management of symptoms, findings in keeping with previous research. ${ }^{17}$ Only one participant believed that palliative care skills were not required in his current specialty (general surgery - in which other studies have shown palliative care can be sub-optimal). ${ }^{9,10}$

In contrast to other studies, although participants acknowledged emotional toll and lack of peer support as potentially challenging, none had been personally affected by these for varying reasons. ${ }^{16,17}$ Challenges faced by junior doctors in other studies such as feeling under or over-supported, limited time with patients, poor inclusion in teams, split job plans, on-call rotas disrupting learning, and limited time with seniors were also not identified here. ${ }^{15,17}$ Again in contrast to previous research with hospice SHOs, the hospice F1s studied here did not perceive conflict between medical and nursing teams, possibly because their placement was too short to detect this. ${ }^{16}$

Unique to this study was the fact that F1s found the hospice learning environment comfortable and less pressurised than hospital environments. They were also conscious of the emphasis on teaching within their placement. These perceptions have not been previously reported in literature and it is impossible to know if these are specific to this hospice, or if this is something inherent to palliative care, related to its slower pace and holistic nature. Participants were divided in opinion as to the potential of hospice placements to medically deskill. This is a new concern, which in other studies was negated by participation in a medical on-call rota during palliative care placements. ${ }^{17}$ As time increased from hospice placement, the effect of the placement on participants' practice seemed to heighten. No studies have found this strengthening of the impact of hospice or palliative placement over time.

Study limitations include the risk of bias; the researcher's previous role as educational supervisor could have compromised consent, influenced responses and skewed results, despite efforts to limit this via third party recruitment and open acknowledgement of roles and bias. This is a small scale study with a small and heterogeneous sample. For example, two participants were older than the others, and when they were discussing emotional toll they felt they had enough life experience to cope. Participants also had a wide range of career aspirations, and this influenced opinion; the aspiring anaesthetist considered lack of complex procedures particularly disadvantageous. This means that results may not be directly transferable when considering other groups of F1s in similar settings. This is especially so because UK hospices vary widely, in terms of size, charitable status and resources. Notwithstanding these provisos, these results provide a real insight into the opportunities and challenges of hospice placements during training and evidence that even a short hospice placement has the potential to change future practice.

\section{Recommendations}

> Consideration should be given to increasing the number of foundation year palliative care posts to enable more trainees to achieve important generic skills in end-of-life care, symptom control and communication. This would not be without challenge: introducing palliative care placements could limit other placement options in already crowded rotations and may not necessarily appeal to trainees. In addition, many hospices are independent of NHS trusts which may be an added complication. However, with the increasing emphasis on community placements in foundation training programmes, hospices (considered a community placement) could present an ideal solution. ${ }^{27}$

> Individual foundation school directors could work together with local palliative care providers to identify potential palliative care placements.

> Studies using serial interviews could be a useful way of enabling a deeper understanding of how hospice placements influence practice over time.

$>$ Research which includes the educational supervisors' views of what competencies are gained during a hospice placement would enable further exploration into the educational value of hospice placements.

$>$ Hospitals should consider how to increase adequately supported exposure of both medical students and foundation year doctors to patients at the end of their life, so providing them with opportunities to observe and develop communication skills in this difficult area.

\section{Conclusion}

A hospice placement can equip trainee doctors with the necessary skills and confidence to recognise, care for and communicate with patients at the end of life and their families. The educational opportunities in hospice placements are valuable, in particular 
for informal experiential learning. The hospice environment is supportive and conducive to learning, and placement value can be maximised by encouraging trainees to do patient-centred tasks and to take on clinical responsibilities. Although most challenges of hospice placements were considered either not relevant or outweighed by advantages, the potential to medically deskill was highlighted. This could be overcome by greater integration of palliative placements with oncology services or participation in an on-call rota. This study has added to the body of literature describing junior doctors' lack of confidence in caring for, and communicating with, dying patients. It has also suggested one possible solution to these problems, through the provision of a short hospice placement for trainees. Training leads should consider the integration of more palliative care or hospice placements into junior doctors' training programmes.

\section{Supplementary material}

Additional supplementary material may be found in the online version of this article at http://futurehospital.rcpjournal.org:

S1 - Interview guide.

S2 - Final index.

\section{References}

1 General Medical Council. Outcomes for graduates. GMC, 2018. www.gmc-uk.org/-/media/documents/dc11326-outcomes-forgraduates-2018_pdf-75040796.pdf [Accessed 23 January 2019].

2 Health Education England. The UK Foundation Programme curriculum. HEE, 2016. https://heeoe.hee.nhs.uk/the_foundation_ programme [Accessed 20 May 2018].

3 Association for Palliative Medicine. Executive summary APM workforce survey. APM, 2016. https://apmonline.org/wp-content/ uploads/2015/04/NEW-MASTER-Executive-Summary-GENERALDETAILS-ON-CALL-AND-7-DAY-SERVICES-APM-WorkforceSurvey-2016-.pdf [Accessed 26 May 2018].

4 Lloyd-Williams M, Macleod RDM. A systematic review of teaching and learning in palliative care within the medical undergraduate curriculum. Med Teach 2004;26:683-90.

5 Gibbins J, McCoubrie R, Forbes K. Why are newly qualified doctors unprepared to care for patients at the end of life? Med Educ 2011:45:389-99.

6 Bowden J, Dempsey K, Boyd K, Fallon M, Murray SA. Are newly qualified doctors prepared to provide supportive and end-of-life care? A survey of foundation year 1 doctors and consultants. J R Coll Physicians Edinb 2013;43:24-8.

7 Charlton R, Smith G. Perceived skills in palliative medicine of newly qualified doctors in the UK. J Palliat Care 2000;16:27-32.

8 Murray-Brown F, Curtis M, Gibbins J. Survey of foundation year 1 doctors caring for the dying; what do they see, do and need to perform this role, following removal of the Liverpool care pathway? Palliat Med 2015;29:975-6.

9 Price S, Schofield S. How do junior doctors in the UK learn to provide end of life care: a qualitative evaluation of postgraduate education. BMC Palliat Care 2015;14:45.
10 Schulman-Green D. How do physicians learn to provide palliative care? J Palliat Care 2003:19:246-52.

11 Cave J, Woolf K, Dacre J, Potts HWW, Jones A. Medical student teaching in the UK: how well are newly qualified doctors prepared for their role caring for patients with cancer in hospital? $\mathrm{Br}$ J Cancer 2007:97:472-8.

12 Linklater GT. Educational needs of foundation doctors caring for dying patients. J R Coll Physicians Edinb 2010;40:13-8.

13 Redman M, Pearce J, Gajebasia S, Johnson M, Finn G. Care of the dying: a qualitative exploration of foundation year doctors' experiences. Med Educ 2017;51:1025-36.

14 Brennan N, Corrigan O, Allard ] et al. The transition from medical student to junior doctor: today's experiences of tomorrow's doctors. Med Educ 2010;44:449-58.

15 Kendall ML, Hesketh EA, Macpherson SG. The learning environment for junior doctor training - what hinders, what helps. Med Teach 2005;27:619-24.

16 Lloyd-Williams M. Senior house officers' experience of a six month post in a hospice. Med Educ 2002;36:45-8.

17 Morrison C, Forbes K. Junior doctors' learning and development in foundation year 1 posts in palliative medicine. Palliat Med 2012;26:851-7.

18 Holloway I, Wheeler S. Qualitative research for nurses, 2nd edn. Oxford: Blackwell Science Ltd, 2002.

19 Brinkmann S, Kvale S. Learning the craft of qualitative research interviewing, 3rd edn. California: Sage, 2015.

20 Hennink M, Hutter I, Bailey A. Qualitative research methods. London: Sage, 2010.

21 Denscombe M. The good research guide for small-scale social research projects, 5th edn. Maidenhead: McGraw-Hill Education, Open University Press, 2014.

22 Ritchie J, Lewis J, Nicholls CM, Ormston R (eds). Qualitative researchers practice: a guide for social science students and researchers, 2nd edn. London: Sage, 2013.

23 Harding J. Qualitative data analysis from start to finish. London: Sage, 2013.

24 Tong A, Sainsbury P, Craig J. Consolidated criteria for reporting qualitative research (COREQ): a 32-item checklist for interviews and focus groups. Int J Qual Health C 2007;19:349-57.

25 Eraut M. Informal learning in the workplace. Stud Cont Educ 2004;26:247-73.

26 Sheehan D, Wilkinson T], Billett S. Interns' participation and learning in clinical environments in a New Zealand hospital. Acad Med 2005;80:302-8.

27 Health Education England. Broadening the foundation programme. Recommendations and implementation guidance. HEE, 2014. www.hee.nhs.uk/our-work/ better-training-better-care/broadening-foundation-programme [Accessed 06 December 2018].

Address for correspondence: Dr Sarah Frearson, palliative medicine consultant, Charing Cross Hospital, Fulham Palace Road, London W2 8RF, UK.

Email: sfrearson@nhs.net 